\section{Fruit Anthocyanin Profile and Berry Color of Muscadine Grape Cultivars and Muscadinia Germplasm}

\author{
Patrick J. Conner ${ }^{1}$ \\ University of Georgia, 4604 Research Way, Tifton, GA 31793 \\ Dan MacLean \\ AgroFresh, 620 Cantrill Drive, Davis, CA 95618
}

Additional index words. berry color, breeding, juice, Vitis munsoniana, Vitis rotundifolia

\begin{abstract}
Anthocyanin content and composition and CIE $1976\left(\mathrm{~L}^{*}, \mathrm{a}^{*}, \mathrm{~b}^{*}\right)$ color space (CIELAB) color coordinates were examined for the skin of 22 muscadine grape (Vitis rotundifolia Michx.) cultivars and Muscadinia Planch germplasm. Analysis of berry skin extracts by high-performance liquid chromatography (HPLC) determined that anthocyanin content varied from less than $100 \mu \mathrm{g} \cdot \mathrm{g}^{-1}$ in bronze and pink berries to over $5500 \mu \mathrm{g} \cdot \mathrm{g}^{-1}$ in highly pigmented black berries. The anthocyanins delphinidin, cyanidin, petunidin, pelargonidin, peonidin, and malvidin were detected in their 3,5 -diglucosidic forms. Analysis of berry color with a colorimeter revealed chroma $\left(C^{*}\right)$ ranged from 2.4 to 22.8 with the highest values occurring in bronze- and red-colored berries. As anthocyanin concentration increased, lightness $\left(L^{*}\right)$ decreased to a low of 20 to 23 in black-colored berries. Pink and red skin colors were primarily a result of lower levels of total anthocyanins, although there was also a shift away from delphinidin and petunidin production toward more cyanidin and peonidin. Malvidin, the most important anthocyanin for muscadine wine and juice color stability, was only abundant in a few clones, all of which had $V$. munsoniana (Simpson ex Munson) Small or $V$. popenoei (Fennell) Small in their pedigree. The interspecific hybrid 'Fennell's 3-way Hybrid' had the largest proportion of malvidin, contributing $\approx 58 \%$ of the total anthocyanin content. This clone also had low levels of delphinidin and high total levels of anthocyanin, making it a promising source for the improvement of muscadine grape pigment profiles.
\end{abstract}

The genus Vitis L. contains two subgenera, Euvitis Planch. (bunch grapes) and Muscadinia (muscadine grapes). The Muscadinia subgenera consists of just three species: $V$. rotundifolia, the common muscadine grape known throughout the southeastern United States, $V$. munsoniana, a semitropical variant of $V$. rotundifolia native to southern Florida, and $V$. popenoei, a tropical native to southern Mexico. The muscadine grape is the only commonly cultivated member of the Muscadinia subgenus. Muscadine grapes are grown throughout the southeastern United States where winter temperatures remain above $-12{ }^{\circ} \mathrm{C}$. Muscadine berries are used for both fresh consumption and for processing into juices and wines. Studies showing the favorable phytochemical profile of muscadine grapes, especially the presence of ellagic acid (Lee and Talcott, 2004), are driving renewed interest in processed muscadine products.

Use of muscadines as a wine and juice grape is hampered by the poor color stability of these products during storage. The primary pigments in grape berries are the anthocyanins, which impart brilliant red and purple colors to grape berries. The common anthocyanidins

Received for publication 10 July 2013. Accepted for publication 03 Sept. 2013.

${ }^{1}$ To whom reprint requests should be addressed; e-mail pconner@uga.edu. found in grapes in order of decreasing stability are malvidin, peonidin, pelargonidin, petunidin, cyanidin, and delphinidin (He et al., 2010). Blueness is enhanced with an increase of free hydroxyl groups, whereas redness intensifies with the raising of the methylation of the hydroxyl groups; thus, malvidin is the reddest individual anthocyanidin ( $\mathrm{He}$ et al., 2010). The presence of adjacent hydroxyl groups of $o$-diphenols are more sensitive to oxidation, making delphinidin, cyanidin, and petunidin less stable (Hrazdina et al., 1970). In contrast, malvidin, peonidin, and pelargonidin have no ortho-positioned hydroxyl groups making them more resistant to oxidation.

In grapes, $O$-glycosylation occurs for anthocyanins and the sugar moiety is typically glucose. The dominant allele involved in the production of diglucosidic anthocyanins is not present in $V$. vinifera resulting in the sole production 3-O-monoglucosides (Jànvàry et al., 2009), whereas other grape species can form 3,5-O-diglucosidic anthocyanins. The 3,5-diglucosides may be more resistant to thermal degradation than the monoglucosides, but they have a decreased ability to form polymeric pigments, making them more prone to oxidation and browning (Flora, 1977; Lee and Talcott, 2004; Sims and Morris, 1986). Many anthocyanins have sugar residues, which are acylated with aromatic or aliphatic acids, which increases their chemical stability (He et al., 2010). Only 3,5diglucosidic anthocyanins in non-acylated forms have been detected in muscadine cultivars (Goldy et al., 1987; Lamikanra, 1998; Lee and Talcott, 2004). However, a survey of native $V$. rotundifolia germplasm uncovered the presence of vines producing low levels of 3-O-monoglycosidoc anthocyanins (Goldy et al., 1989).

Muscadine juice color quality and stability are affected by the total amount of anthocyanins in the berry, the relative proportion of the individual anthocyanins, and the lack of intramolecular copigmentation (Flora, 1977, 1978; Sims and Bates, 1994; Talcott et al., 2003; Talcott and Lee, 2002). Ballinger et al. (1974) examined the anthocyanin profile of $39 \mathrm{~V}$. rotundifolia clones and found that delphinidin was the predominant anthocyanin in over $90 \%$ of the samples. Despite the predominance of delphinidin, delphinidin content was not associated with visual color ratings of the wines. Wines with good red color were strongly associated with high contents of malvidin and to a lesser extent petunidin. Unfortunately, most muscadine cultivars examined had low levels of both malvidin and petunidin. Two notable exceptions were 'Tarheel' and 'Noble', which contained good amounts of malvidin and petunidin and produced wines of acceptable color. Since that early work, several authors have used HPLC to better examine the anthocyanin profile of muscadine grapes (Goldy et al., 1989; Huang et al., 2009; Lamikanra, 1988; Lee and Talcott, 2004; Sandhu and Gu, 2010). This work largely corroborated earlier work indicating that delphinidin was the predominant anthocyanin and malvidin was relatively uncommon in most clones.

Attractive color is a main sensory characteristic of fruit products. Muscadine berries typically occur as a very dark purple or black color or as an unpigmented or lightly blushed bronze (greenish yellow) color. Marketplaces typically sell both colors and many consumers have a preference for one over the other. Despite the predominance of the bronze and black colors, other colors are available ranging from lavender to purple and pink through red shades. Breeding cultivars with new skin colors may open up new markets for muscadines and is a priority in breeding programs (Conner, 2010). The most popular method of measuring the surface color of a fruit involves instruments that measure the surface reflectance and relates it to CIELAB coordinates of $\mathrm{L}^{*}, \mathrm{a}^{*}$, and $\mathrm{b}^{*}$. Total anthocyanin content and relative amounts of individual anthocyanins were found to be significantly correlated to CIELAB coordinates in $V$. vinifera berries (Liang et al., 2011).

Early work in the anthocyanin profile of muscadine grapes was limited by the resolution of techniques used, whereas most modern studies of the pigment profile of muscadine grapes have made use of a relatively narrow pool of germplasm consisting generally of clones that are predominantly black in color. In addition, there is no known work that measures the pigment profile of $V$. munsoniana 
or $V$. popenoei germplasm. The goal of this study was to examine an array of colored muscadine germplasm, including germplasm containing $V$. popenoei and $V$. munsoniana in their background, to determine the pigment profile of variously colored muscadine berries.

\section{Materials and Methods}

Plant material. Vines were grown at the University of Georgia (UGA)-Tifton Campus located in Tift County, GA (lat. 33 $53^{\prime} 7.69^{\prime \prime} \mathrm{N}$, long. $83^{\circ} 25^{\prime} 20.30^{\prime \prime} \mathrm{W}$ ). Muscadine clones used in this work are a mixture of historical and recently released muscadine cultivars as well as advanced selections from the UGA breeding program and were chosen to include a range of visually identified skin colors. The female $V$. munsoniana selection 'Marsh' and the male $V$. munsoniana selection 'Thornhill' were obtained from the National Clonal Germplasm Repository (NCGR) for Fruit and Nut Crops located in Davis, CA. Selections Ga. 8-6-14, Ga. 8-6-26, and Ga. 8-6-28 were obtained by crossing a purple-fruited female muscadine selection to 'Thornhill'. Selections Ga. 9-15-21 and Ga. 9-15-49 were obtained by planting open-pollinated seed obtained from a 'Marsh' vine surrounded by pigmented and unpigmented muscadine vines. 'Fennell's 3-way Hybrid', $V$. popenoei $\times(V$. rotundifolia $\times V$. munsoniana), was also obtained from the NCGR at Davis, CA. Genomic composition of the various interspecific hybrids (Table 1) was determined by tracing pedigrees either through published pedigrees (Clark, 1997), NCGR system records, or University of Georgia breeding program records.

All vines were trained to a single wire trellis with two cordons per vine and spaced $3 \mathrm{~m}$ between plants within the row and $4.5 \mathrm{~m}$ between rows. Diseases and insects were controlled according to commercial guidelines (Poling et al., 2003). All berry samples were collected at their ripening time as judged by previous years' maturation date and sweetness and softness of the berries. Color measurements and anthocyanin extractions were carried out within $1 \mathrm{~d}$ of harvest.

Berry skin color measurement. Berry skin color was measured at the equator of the berry using a Konica Minolta CR-400 (8 mm aperture, D65 illuminant) handheld colorimeter (Konica Minolta, Ramsey, NJ). The colorimeter was calibrated with a white standard calibration plate, and color was measured as $\mathrm{L}^{*}, \mathrm{a}^{*}, \mathrm{~b}^{*}$ coordinates. A single measurement was recorded for each berry and 10 replicate berries were measured for each clone. The value of $L^{*}$ describes the degree of darkness or lightness with $\mathrm{L}=0$ being black and $\mathrm{L}=100$ white. Before analysis, $\mathrm{a}^{*}$ and $\mathrm{b}^{*}$ coordinates were transformed into chroma $\left(C^{*}\right)$ and hue angle $\left(h^{\circ}\right)$ using the equations: $\mathrm{C}^{*}=\left(\mathrm{a}^{* 2}+\mathrm{B}^{* 2}\right)^{1 / 2}$ and $h^{\circ}=\tan ^{-1}\left(\mathrm{~b}^{*} / \mathrm{a}^{*}\right)$ (McGuire, 1992). Richness of color is represented by $\mathrm{C}^{*}$ and $h^{\circ}$ represents the dominant color wavelength where $0^{\circ}=$ red-purple, $90^{\circ}=$ yellow, $180^{\circ}=$ bluish green, $270^{\circ}=$ blue.

HPLC-DAD sample preparation and analysis. Skins from five muscadine grapes per clone per replication were combined, flash-frozen in liquid nitrogen, and ground to a fine powder with a mortar and pestle. Reported values are the average of four replications per clone. Approximately $1 \mathrm{~g}$ was extracted with $10 \mathrm{~mL}$ of $\mathrm{MeOH}$ :water: formic acid $(88 \%)$ [60:37:3 (v/v)] buffer, vortexed, and extracted overnight at $4{ }^{\circ} \mathrm{C}$. After extraction, a 1-mL aliquot was centrifuged at $25,000 \times g$ for $15 \mathrm{~min}$ at $8{ }^{\circ} \mathrm{C}$ in a Beckman-Coulter Allegra 25R centrifuge equipped with a TA-15-1.5 rotor. The sample was then transferred into $1.8-\mathrm{mL}$ amber
HPLC vial fitted with a polytetrafluoroethylene screw-on cap. Anthocyanins were separated and identified using an Agilent 1200 series HPLC (Foster City, CA) system equipped with an inline continuous vacuum solvent degasser, binary pump, temperature-controlled autosampler and column compartments, and a photodiode-array detector (PDA), all controlled by Chemstation (rev. B.03.01) software package (Santa Clara, CA). Solvents used were A: $5 \%$ formic acid and B: acetonitrile at a flow rate of $0.400 \mathrm{~mL} \cdot \mathrm{min}^{-1}$. The gradient (expressed as $\% \mathrm{~B}$ ) was 0 to $2 \mathrm{~min}$, $3 \%$; $16 \mathrm{~min}, 13 \% ; 20 \mathrm{~min}, 50 \% ; 20$ to $24 \mathrm{~min}$, $100 \%$; 24 to $28 \mathrm{~min}, 3 \%$. The autosampler compartment was maintained at $4{ }^{\circ} \mathrm{C}$. The volume of injection for both samples and standards was $5 \mu \mathrm{L}$ (draw speed of $100 \mu \mathrm{L} \cdot \mathrm{min}^{-1}$ ). The flavonoid compounds were retained using an Agilent Zorbax Eclipse XDB-C18 column $(100 \mathrm{~mm} \times 3 \mathrm{~mm} \times 3.5 \mu \mathrm{m})$ protected by a guard column $(12.5 \mathrm{~mm} \times$ $4.6 \mathrm{~mm} \times 5 \mu \mathrm{m})$ of the same phase, all held at $30^{\circ} \mathrm{C}$ within the column compartment. Eluted compounds were detected using the PDA equipped with a semimicro flow cell with a full spectral scan set from 190 to $650 \mathrm{~nm}$ (2-nm steps) and monitored at $520 \mathrm{~nm}$ for the detection of anthocyanins with a bandwidth of $4 \mathrm{~nm}$.

Compound identification and quantification. Fractions for each peak were collected and concentrated to near dryness using a rotor evaporator. A Bruker Autoflex matrix-assisted laser desorption ionization-time of flight/mass spectroscopy was used to produce ions $(\mathrm{m} / \mathrm{z})$, which were compared against libraries and published literature (Huang et al., 2009) to identify peaks of interest. Authentic standards for the majority of the peaks are not available; thus, all peaks are expressed in cyanidin 3-Ogalactoside (Ideain chloride; Indofine Chemical Company, Hillsborough, NJ) equivalents.

Table 1. Genomic composition and colorimetric parameters of berry skins of Muscadinia clones.

\begin{tabular}{|c|c|c|c|c|c|c|c|}
\hline Clone & $\begin{array}{c}\text { Percent } \\
V . \text { rotundifolia }\end{array}$ & $\begin{array}{c}\text { Percent } \\
\text { V. } \text { munsoniana }^{z}\end{array}$ & $\begin{array}{c}\text { Percent } \\
V . \text { popenoei }^{\mathrm{z}}\end{array}$ & Berry color $^{y}$ & $\mathrm{~L}^{*}$ & $\mathrm{C}^{*}$ & $\begin{array}{c}\text { Hue } \\
\text { angle }\left(h^{\circ}\right)\end{array}$ \\
\hline$\overline{\text { Cowart }}$ & 100 & & & Black & $22.2 \mathrm{ab}^{\mathrm{x}}$ & $7.7 \mathrm{~cd}$ & $13.7 \mathrm{a}-\mathrm{c}$ \\
\hline Fennell's 3-way Hybrid & 25 & 25 & 50 & Black & $21.2 \mathrm{a}$ & $5.8 \mathrm{a}-\mathrm{d}$ & $1.5 \mathrm{a}$ \\
\hline Fry & 100 & & & Bronze & $45.6 \mathrm{f}$ & $20.2 \mathrm{f}$ & $91.8 \mathrm{e}$ \\
\hline Ga. $1-2-124$ & 100 & & & Black & $22.1 \mathrm{ab}$ & $6.4 \mathrm{a}-\mathrm{d}$ & $17.0 \mathrm{a}-\mathrm{c}$ \\
\hline Ga. 1-6-14 & 100 & & & Pink & $38.6 \mathrm{e}$ & $16.1 \mathrm{ef}$ & $63.6 \mathrm{~d}$ \\
\hline Ga. $19-73$ & 100 & & & Black & $22.9 \mathrm{ab}$ & $10.0 \mathrm{~d}$ & $16.7 \mathrm{a}-\mathrm{c}$ \\
\hline Ga. $5-1-28$ & 100 & & & Red & $32.3 \mathrm{~cd}$ & $17.3 \mathrm{ef}$ & $24.1 \mathrm{bc}$ \\
\hline Ga. 5-1-34 & 100 & & & Red & $27.3 \mathrm{bc}$ & $14.9 \mathrm{e}$ & $19.0 \mathrm{a}-\mathrm{c}$ \\
\hline Ga. $8-1-338$ & 100 & & & Red & $47.7 \mathrm{f}$ & $22.8 \mathrm{~g}$ & $26.0 \mathrm{bc}$ \\
\hline Ga. $8-6-14$ & 50 & 50 & & Black & $21.4 \mathrm{a}$ & $2.9 \mathrm{ab}$ & $20.9 \mathrm{a}-\mathrm{c}$ \\
\hline Ga. 8-6-26 & 50 & 50 & & Black & $22.7 \mathrm{ab}$ & $5.8 \mathrm{a}-\mathrm{c}$ & $27.4 \mathrm{bc}$ \\
\hline Ga. $8-6-28$ & 50 & 50 & & Black & $20.4 \mathrm{a}$ & $2.7 \mathrm{ab}$ & $18.2 \mathrm{a}-\mathrm{c}$ \\
\hline Ga. $9-15-21$ & 50 & 50 & & Black & $21.7 \mathrm{a}$ & $4.4 \mathrm{a}-\mathrm{c}$ & $17.3 \mathrm{a}-\mathrm{c}$ \\
\hline Ga. 9-15-49 & 50 & 50 & & Black & $21.2 \mathrm{a}$ & $3.3 \mathrm{ab}$ & $24.1 \mathrm{bc}$ \\
\hline Lake Charles & 100 & & & Black & $20.4 \mathrm{a}$ & $2.4 \mathrm{a}$ & $13.0 \mathrm{a}-\mathrm{c}$ \\
\hline Lane & 100 & & & Black & $21.0 \mathrm{a}$ & $3.4 \mathrm{ab}$ & $16.9 \mathrm{a}-\mathrm{c}$ \\
\hline Marsh & & 100 & & Black & $22.3 \mathrm{ab}$ & $4.9 \mathrm{a}-\mathrm{c}$ & $33.7 \mathrm{c}$ \\
\hline Noble & 94 & 6 & & Black & $23.2 \mathrm{ab}$ & $6.7 \mathrm{~b}-\mathrm{d}$ & $15.7 \mathrm{a}-\mathrm{c}$ \\
\hline Regale & 98 & 2 & & Black & $21.3 \mathrm{a}$ & $3.1 \mathrm{ab}$ & $30.5 \mathrm{c}$ \\
\hline Scarlett & 100 & & & Pink & $34.0 \mathrm{de}$ & $16.3 \mathrm{ef}$ & $33.3 \mathrm{c}$ \\
\hline Supreme & 100 & & & Black & $22.2 \mathrm{ab}$ & $4.1 \mathrm{a}-\mathrm{c}$ & $8.4 \mathrm{ab}$ \\
\hline Tarheel & 87 & 13 & & Black & $21.9 \mathrm{a}$ & $3.3 \mathrm{ab}$ & $28.8 \mathrm{bc}$ \\
\hline
\end{tabular}

${ }^{\mathrm{z}}$ Genomic composition based on pedigree.

${ }^{\mathrm{y}}$ Berry color based on visual classification.

${ }^{\mathrm{x}}$ Means within a column and followed by the same letter are not significantly different (Holm-Sidak method $\left.P=0.05\right)$. 
A standard curve ranging from 0.2 to $5 \mu \mathrm{g}$ was used to quantify the compounds $\left(R^{2}=0.9999\right)$.

Statistical analysis. Anthocyanin content and percentage of individual anthocyanins produced in 2010 and 2011 were analyzed independently because a larger number of clones was examined in 2011 than in 2010. Anthocyanin content within a year was examined using one-way analysis of variance (ANOVA) with mean separation by the Holm-Sidak method $(P=0.05)$. Percentage of individual anthocyanins was analyzed using one-way ANOVA after arcsine-square root transformation with mean separation by the Holm-Sidak method $(P=0.05)$. Clone, year, and clone $\times$ year significance tests were performed using two-way ANOVA using only those clones tested in both years. Significant differences in anthocyanin levels between years within a clone were determined with a Holm-Sidak test $(P=0.05)$. Associations among anthocyanin profile and color parameters were determined using Pearson product moment correlation coefficients of the mean values of cultivars in 2011. Statistical analysis was performed using SigmaPlot 12.3 statistical software (Systat Software Inc., San Jose, CA).

\section{Results}

Berry skin colors and CIELAB coordinates. Black-colored berries had L* values of 20 to 23 (Table 1). As berry color changed from black to red to pink to bronze, $\mathrm{L}^{*}$ increased. The one exception was Ga. 8-1-338, which had very bright red berries with an $\mathrm{L}^{*}$ value not significantly different from the bronze-colored 'Fry'. Values of $\mathrm{C}^{*}$ ranged from 2.4 to 22.8 with the highest $\mathrm{C}^{*}$ values occurring in $\mathrm{Ga}$. 8-1-338 followed by the other red-, pink-, and bronzecolored clones. Black-colored clones all had $\mathrm{C}^{*}$ values of 10.0 or less. Values of $h^{\circ}$ ranged from 1.4 in 'Fennell's 3-way Hybrid' to 91.8 in bronze-colored 'Fry'. Berry $h^{\circ}$ had less of an effect on the visual estimation of berry color than did $\mathrm{C}^{*}$ because most pigmented berries ranged in $h^{\circ}$ between 8 and 34 with no strong differences between the colors (Fig. 1). The pink-colored Ga. 1-6-14 has a very light pink blush over an otherwise bronze-colored berry giving it a more yellow $h^{\circ}$ of 63.6.

Anthocyanin content and composition. Anthocyanin content of berry skins ranged from less than $100 \mu \mathrm{g} \cdot \mathrm{g}^{-1}$ in bronze and pink clones to over $5500 \mu \mathrm{g} \cdot \mathrm{g}^{-1}$ in highly pigmented black clones (Table 2). Anthocyanin content varied significantly by year with an average in 2010 of $2612 \mu \mathrm{g} \cdot \mathrm{g}^{-1}$ and an average of $1991 \mu \mathrm{g} \cdot \mathrm{g}^{-1}$ in 2011 . Clone $\times$ year interactions were not significant for total anthocyanin content.

Anthocyanins were detected only in their 3,5-diglucosidic forms. Delphinidin and cyanidin were the most common anthocyanins and were detected in nearly equal proportions (Table 2). Petunidin and peonidin were the next most common anthocyanins with their proportion varying by year. Malvidin levels were variable with most clones having low contents, but a few clones had high levels. Pelargonidin was rare and was not detected in the majority of the clones. It was most commonly found in clones with a pink or red berry color. It was also found in the wine cultivar Noble, which has $V$. munsoniana in its background.

The proportion of cyanidin did not vary between years, whereas all other anthocyanins varied significantly by year (Table 2 ). Clone $\times$ year interactions were significant for each anthocyanin except cyanidin and malvidin. The majority of the changes across years occurred in clones with bronze-, pink-, or red-colored berries. Nearly all of the changes resulted in a lower proportion of delphinidin, petunidin, malvidin, and pelargonidin and a higher proportion of cyanidin and peonidin in 2011 as compared with 2010 . The one exception to this was 'Fry', which saw an increase in delphinidin and lower levels of petunidin and peonidin in 2011 .

Relationship among CIELAB parameters and anthocyanin content and composition. There were significant positive correlations among all color parameters (Table 3 ). The value of $\mathrm{L}^{*}$ decreased with increasing total anthocyanins reaching a lower limit of 20 to 22 (Fig. 2). The proportion of petunidin increased and the proportion of peonidin decreased with increasing levels of anthocyanins, whereas the proportion of other anthocyanins was unaffected by total anthocyanin concentration (Table 3). Although not all correlations among anthocyanin proportions were significant, pigments were grouped so that positive associations occurred among cyanidin, peonidin, and pelargonidin in one group and delphinidin, petunidin, and malvidin in the other group with negative associations across groups.

\section{Discussion}

Muscadine berries in this study ranged in color from bronze through darkening shades of pink, red, red-black, to black. Darker colored muscadines ranged from black to purple to red-black with shades varying resulting from ripeness and sun exposure. As a result of the difficulty of discretely classifying the color of these samples, all of these clones were visually labeled as black. CIELAB color parameters provide a more objective means of classifying colors. High levels of anthocyanins in the berry skin led to decreasing $\mathrm{L}^{*}$ and $\mathrm{C}^{*}$ values, resulting in a black berry color. Pink- and red-colored berries are of interest because they represent a possible new market class of muscadine, distinct from the bronze- or black-colored berries. Pink and red colors were primarily

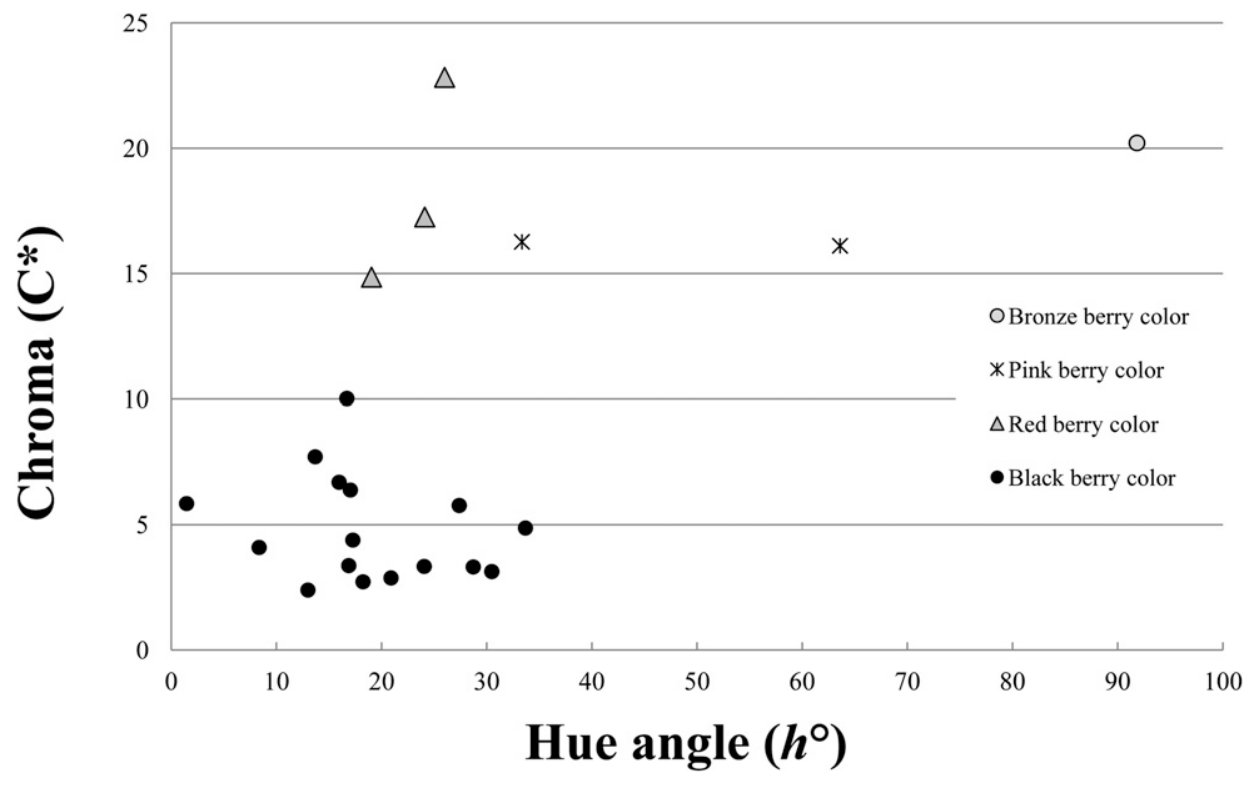

Fig. 1. Distribution of berry skin color of 22 Muscadinia clones based on chroma $\left(C^{*}\right)$ and hue angle $\left(h^{\circ}\right)$ coordinates. Each point represents the average of 10 berries measured at the equatorial plane. Bronze, pink, red, and black berry colors were assigned by visual classification of skin color. 
Table 2. Anthocyanin content and composition of Muscadinia clones measured in 2010 and 2011.

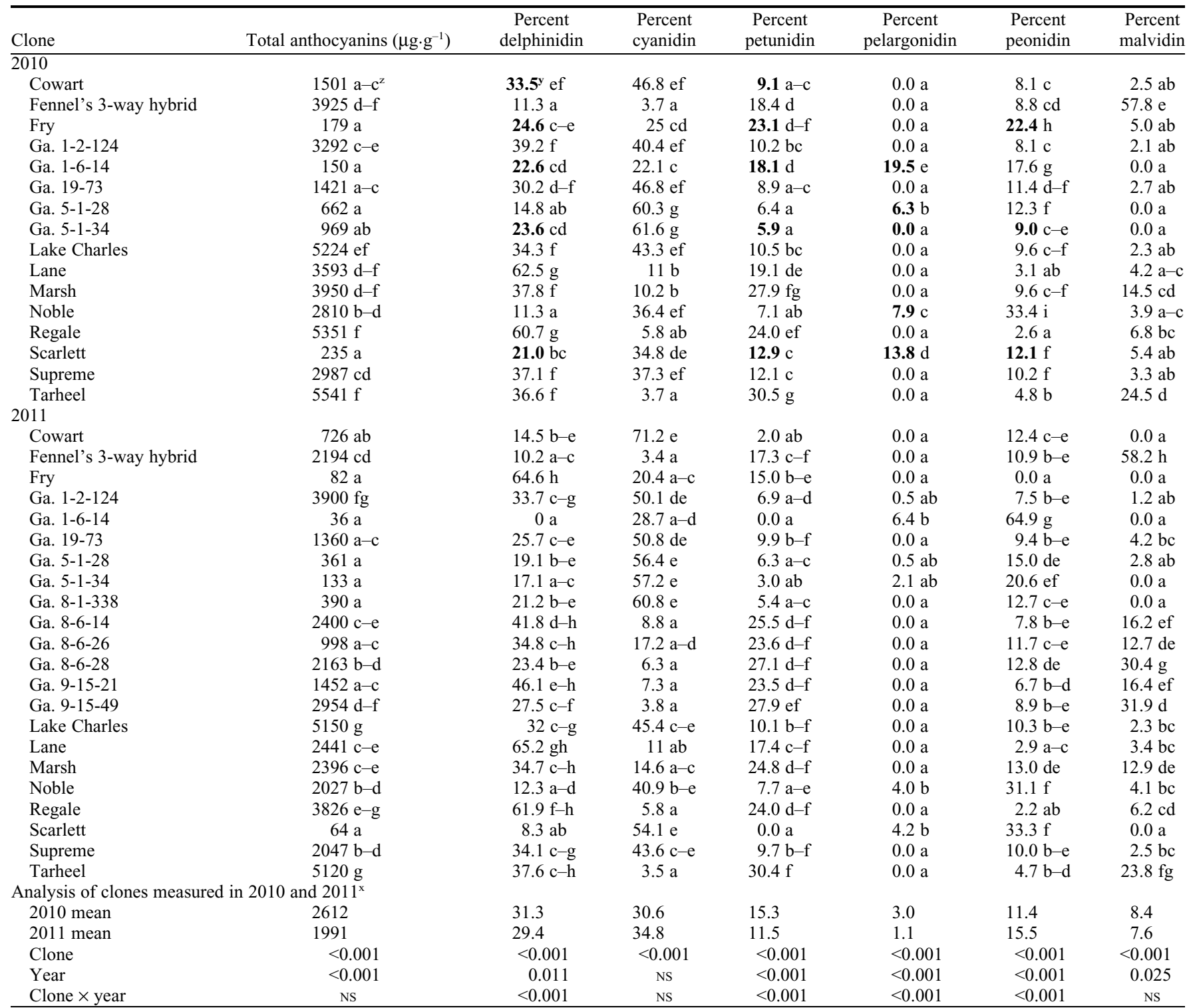

${ }^{\mathrm{z}}$ Means within a column and year followed by the same letter are not significantly different (one-way analysis of variance, Holm-Sidak method $P=0.05$ ).

${ }^{\mathrm{y}}$ Entries in bold were significantly different between 2010 and 2011 based on two-way analysis of variance using clones measured in both 2010 and 2011 (HolmSidak method $P=0.05$ ).

${ }^{\mathrm{x}}$ Clones measured in both 2010 and 2011 were analyzed with two-way analysis of variance (Holm-Sidak method $P=0.05$ ) to determine the significance of clone, year, and clone $\times$ year interactions.

NS = nonsignificant.

Table 3. Pearson correlation coefficients among CIELAB color parameters and anthocyanin content and profile of berry skins of Muscadinia clones.

\begin{tabular}{|c|c|c|c|c|c|c|c|c|c|}
\hline & $\mathrm{L}^{*}$ & $\mathrm{C}^{*}$ & $h^{\circ}$ & $\begin{array}{c}\text { Total anthocyanins } \\
\left(\mu \mathrm{g} \cdot \mathrm{g}^{-1}\right)\end{array}$ & $\begin{array}{c}\text { Percent } \\
\text { delphinidin }\end{array}$ & $\begin{array}{l}\text { Percent } \\
\text { cyanidin }\end{array}$ & $\begin{array}{c}\text { Percent } \\
\text { petunidin }\end{array}$ & $\begin{array}{c}\text { Percent } \\
\text { pelargonidin }\end{array}$ & $\begin{array}{c}\text { Percent } \\
\text { peonidin }\end{array}$ \\
\hline$h^{\circ}$ & $0.867^{* *}$ & $0.696 * *$ & & & & & & & \\
\hline Total anthocyanins $\left(\mu \mathrm{g} \cdot \mathrm{g}^{-1}\right)$ & $-0.636^{* *}$ & $-0.754 * *$ & NS & & & & & & \\
\hline Percent cyanidin & NS & $0.550^{* *}$ & NS & NS & $-0.477 *$ & & & & \\
\hline Percent petunidin & $-0.479 *$ & $-0.645^{* *}$ & NS & $0.526^{*}$ & $0.552 * *$ & $-0.879 * *$ & & & \\
\hline Percent pelargonidin & NS & NS & NS & NS & $-0.587 * *$ & NS & $-0.570^{* *}$ & & \\
\hline
\end{tabular}

Ns, ${ }^{*}, * *$ Nonsignificant or significant at $P=0.05$ or 0.01 , respectively.

a result of decreased levels of total anthocyanins, although there was also a shift away from delphinidin and petunidin production toward more cyanidin and peonidin. Selection
Ga. 8-1-338 was of particular interest because it had much higher $\mathrm{L}^{*}$ and $\mathrm{C}^{*}$ values in comparison with the other two red-colored clones (Table 1). However, Ga. 8-1-338 was not different from the other two red clones in either anthocyanin content or pigment profile (Table 2), and it is not clear why berry color differed so markedly. 


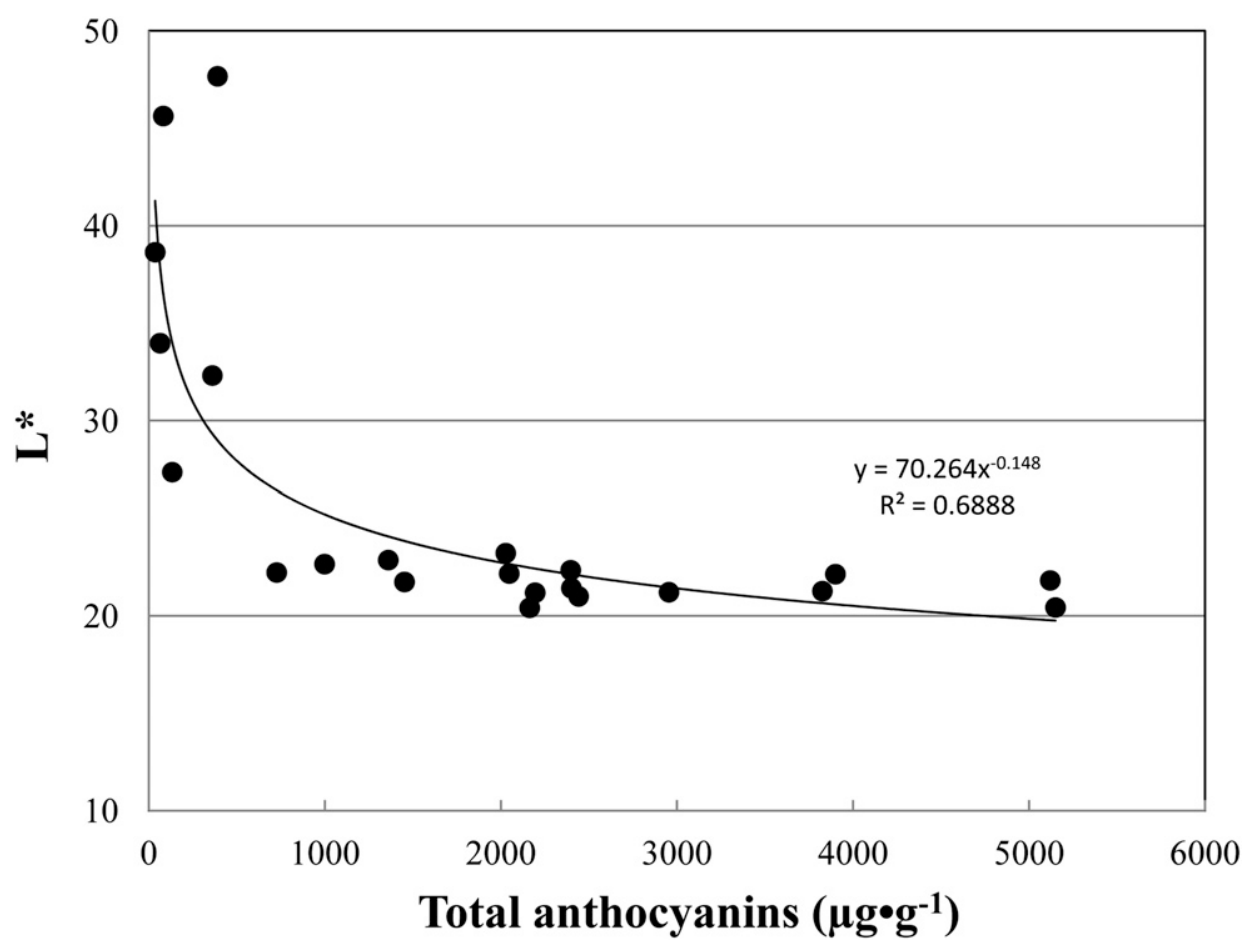


measured for $L^{*}$ coordinates and four replications averaged for anthocyanin concentration.

Results of this study were similar to most previous research reports in that only 3,5diglucosidic forms of the anthocyanins were found. Interestingly, several clones were found to have small amounts of pelargonidin. The presence of pelargonidin has only been reported previously in two reports (Sandhu and Gu, 2010; Talcott and Lee, 2002) in the cultivar Noble. Its absence from other published reports is likely because it is relatively low in concentration and that it is only detected in a few clones, most prominently in the relatively rare pink-colored clones. Pelargonidin is only occasionally detected in other Vitis spp., usually in low concentrations where the production of flavonoids with more than one hydroxyl group is favored ( $\mathrm{He}$ et al., 2010).

Differences were found in both total content and relative content of the various anthocyanins between 2010 and 2011. Previous work indicates that grape berry anthocyanin levels and composition can vary with different light levels (Mazza, 1995), irrigation levels (Buschetti et al., 2011; Castellarin et al., 2007; Sofo et al., 2012), ripeness (Lamikanra, 1988; Lee and Talcott, 2004; Sims and Bates, 1994), and temperature (Mori et al., 2007). Lower daytime temperatures in August of $2010\left(33.1{ }^{\circ} \mathrm{C}\right.$ average high) compared with August of $2011\left(34.6^{\circ} \mathrm{C}\right.$ average high) may have led to decreased total anthocyanins in 2011. In addition, we have noted that pigmentation appears to darken in berries with high sun exposure and cropload or pruning differences may have led to more sun exposure to the berries in 2010. In this work, pigment profiles were mostly stable across years in the black-colored clones but varied substantially in the other colors. The cause of this difference is unknown; however, the total amount of specific anthocyanins in the pink- and bronze-colored clones is low and in some cases approaches the limit of detection of the instrument.

Delphinidin was reported to be the most common anthocyanin in muscadine berries in several research reports (Goldy et al., 1987; Lamikanra, 1988; Lee and Talcott, 2004). Averaged across all clones, we found delphinidin and cyanidin occurred in roughly equal proportions. The higher proportion of cyanidin that we found may be attributable in part to the differences in clones examined, particularly the presence of several red- and pink-colored clones. However, even when comparing a single clone such as 'Noble', estimates for percentage delphinidin were $37 \%$ to $34 \%$ in three studies (Goldy et al., 1987; Lamikanra et al., 1988; Lee and Talcott, 2004) as compared with $12 \%$ to $10 \%$ in this study and a previous study ( $\mathrm{Zhu}$ et al., 2012). Differences in anthocyanin profiles between their findings and previous work led Lamikanra (1988) to conclude that the ratio of anthocyanin contents is not consistent and may vary as a result of geographic locations and climatic conditions.

The consistency of the 'Noble' anthocyanin profile in this study between years and the use of mass spectrophotometry should rule out the misidentification of peaks. It is possible, however, that misidentification has led to different clones being labeled as 'Noble' muscadine and that these clones have different anthocyanin profiles. Alternatively, the relative abundance of $3^{\prime}, 4^{\prime}$, and $5^{\prime}$ hydroxylated (delphinidin, petunidin, malvidin) to $3^{\prime}, 4^{\prime}$-hydroxylated (cyanidin and peonidin) anthocyanins is increased in water-stressed $V$. vinifera plants (Castellarin et al., 2007). All of the vines used in this study were given ample irrigation, which might favor the production of dihydroxylated anthocyanins in comparison with nonirrigated plants. It is unstated if the plants in previous studies were irrigated.

Anthocyanin production pathways indicate that peonidin is produced from cyanidin, whereas petunidin and malvidin are produced from delphinidin (He et al., 2010). Thus, it is expected that high levels of peonidin and cyanidin would occur in the same clones, whereas delphinidin, petunidin, and malvidin would also occur together. Our correlation data generally confirm this hypothesis (Table 3 ), although not all the predicted correlations were significant. For instance, percent peonidin was negatively correlated with percent delphinidin and petunidin but was not correlated with percent cyanidin, presumably because the formation of peonidin removes the precursor, cyanidin.

The most important anthocyanins in terms of juice color stability are malvidin and, to a lesser extent, peonidin (Talcott et al., 2003). Malvidin was the second least abundant anthocyanin and was completely absent from several of the clones (Table 2). However, a few clones had relatively high levels of malvidin. By far the highest percentage of malvidin was found in the interspecific hybrid 'Fennell's 3-way Hybrid' (Mortensen et al., 1994), which had 58\% malvidin, and the percentage malvidin plus peonidin was nearly $70 \%$. These levels are similar to those of $V$. vinifera wine grapes such as 'Cabernet Sauvignon' (Goldy et al., 1986) and compares 
favorably to the current predominant red juice muscadine cultivar Noble, which had $\approx 36 \%$ malvidin plus peonidin. Total anthocyanin content in 'Fennel's 3-way Hybrid' was higher than in the juice cultivar Noble in 2010 and similar to 'Noble' in 2011. Importantly, the levels of delphinidin, which is the least stable anthocyanin, were quite low in 'Fennel's 3way Hybrid', $\approx 10 \%$, similar to 'Noble'. Other clones with high levels of malvidin were $\mathrm{Ga}$. 8-6-28, Ga. 9-15-49, 'Spalding', and 'Tarheel'. However, all of these had higher levels of delphinidin than 'Fennell's 3-way Hybrid'.

All clones with over $10 \%$ malvidin had some degree of $V$. popenoei and/or $V$. munsoniana in their pedigree (Tables 1 and 2). Unlike $V$. vinifera, which has also been suggested as a source to improve muscadine pigments (Goldy et al., 1986; Olmo, 1971), both of these species share the same chromosome number as $V$. rotundifolia and appear to be fully fertile with $V$. rotundifolia (data not shown). They therefore have the potential to serve as sources of more favorable pigment profiles to muscadine juice grapes. Both, however, have much smaller berry size than muscadines and hybrids will likely need several generations of backcrossing to $V$. rotundifolia for the berries to reach the size and juice quality needed for a successful muscadine cultivar.

\section{Literature Cited}

Ballinger, W., E. Maness, W. Nesbitt, D. Makus, and D. Carroll, Jr. 1974. A comparison of anthocyanins and wine color quality in black grapes of 39 clones of Vitis rotundifolia Michx. J. Amer. Soc. Hort. Sci. 99:338-341.

Buschetti, B., M. Mathews, L. Falginella, E. Peterlunger, and S. Castellarin. 2011. Effect of water deficit on Merlot grape tannins and anthocyanins across four seasons. Sci. Hort. 128:297-305.

Castellarin, S., A. Pfeiffer, P. Sivilotti, M. Degan, E. Peterlunger, and B. Di Gaspero. 2007. Transcriptional regulation of anthocyanin biosynthesis in ripening fruits of grapevine under seasonal water deficit. BMC Genomics 7:12.
Clark, J. 1997. Grapes, p. 248-299. In: The Brooks and Olmo register of fruit \& nut varieties. ASHS Press, Alexandria, VA.

Conner, P.J. 2010. A century of muscadine grape (Vitis rotundifolia Michx.) breeding at the University of Georgia. J. Amer. Pom. Soc. 64: 78-82.

Flora, L. 1977. Processing and quality characteristics of muscadine grapes. J. Food Sci. 42:1312.

Flora, L. 1978. Influence of heat, cultivar and maturity on the anthocyanidin-3,5-diglucosides of muscadine grapes. J. Food Sci. 43:1819-1821.

Goldy, R., W. Ballinger, and E. Maness. 1986. Fruit anthocyanin content of some Euvitis $\times$ Vitis rotundifolia hybrids. J. Amer. Soc. Hort. Sci. 111:955-960.

Goldy, R., W. Ballinger, E. Maness, and W. Swallow. 1987. Pigment correlations between fruit and vegetative tissue in 10 selections of muscadine grape. J. Amer. Soc. Hort. Sci. 112: 883-885.

Goldy, R., E. Maness, H. Stiles, J. Clark, and M. Wilson. 1989. Pigment quantity and quality characteristics of some native Vitis rotundifolia Michx. Amer. J. Enol. Viticult. 40:253-258.

He, F., L. Mu, G. Yan, N. Liang, Q. Pan, J. Wang, M. Reeves, and C. Duan. 2010. Biosynthesis of anthocyanins and their regulation in colored grapes. Molecules 15:9057-9091.

Hrazdina, G., A. Borzell, and W. Robinson. 1970. Studies on the stability of the anthocyanidins3,5-diglucosides. Amer. J. Enol. Viticult. 21: 201-204.

Huang, Z., B. Wang, P. Williams, and R. D. Pace. 2009. Identification of anthocyanins in muscadine grapes with HPLC-ESI-MS. LWT-Food Science and Technology 42:819-824.

Jànvàry, L., T. Hoffmann, J. Pfeiffer, L. Hausmann, R. Topfer, T. Fischer, and W. Schwab. 2009. A double mutation in the anthocyanin 5-Oglucosyltransferase gene disrupts enzymatic activity in Vitis vinifera L. J. Agr. Food Chem. 57:3512-3518.

Lamikanra, O. 1988. Development of anthocyanin pigments in muscadine grapes. HortScience 23:597-599.

Lee, J. and S. Talcott. 2004. Fruit maturity and juice extraction influences ellagic acid derivatives and other antioxidant polyphenolics in muscadine grapes. J. Agr. Food Chem. 52:361-366.

Liang, Z., M. Sang, P. Fan, B. Wu, L. Wang, S. Yang, and S. Li. 2011. CIELAB coordinates in response to berry skin anthocyanins and their composition in Vitis. J. Food Sci. 76:490-497.

Mazza, G. 1995. Anthocyanins in grapes and grape products. Crit. Rev. Food Sci. Nutr. 35:341-371.

McGuire, R. 1992. Reporting of objective color measurements. HortScience 27:1254-1255.

Mori, K., N. Goto-Yamamoto, M. Kitayama, and K. Hashizume. 2007. Loss of anthocyanins in red-wine grape under high temperature. J. Expt. Bot. 58:1935-1945.

Mortensen, J., J. Harris, D. Hopkins, and P. Anderson. 1994. 'Southern Home': An interspecific hybrid grape with ornamental value. HortScience 29:1371-1372.

Olmo, H. 1971. Vinifera rotundifolia hybrids as wine grapes. Amer. J. Enol. Viticult. 22:87-91.

Poling, B., C. Mainland, W. Bland, B. Cline, and K. Sorenson. 2003. Muscadine grape production guide. N.C. State Ext. Serv. Bul. AG-94. Raleigh, NC.

Sandhu, A. and L. Gu. 2010. Antioxidant capacity, phenolic content, and profiling of phenolic compounds in the seeds, skin, and pulp of Vitis rotundifolia (muscadine grapes) as determined


58:4681-4692.

Sims, C. and R. Bates. 1994. Effects of skin fermentation time on phenols, anthocyanins, ellagic acid sediment, and sensory characteristics of a red Vitis rotundifolia wine. Amer. J. Enol. Viticult. 45:56-62.

Sims, C. and J. Morris. 1986. Effects of acetaldehyde and tannins on the color and chemical age of red muscadine (Vitis rotundifolia) wine. Amer. J. Enol. Viticult. 37:163-165.

Sofo, A., V. Nuzzo, G. Tataranni, M. Manfra, M. De Nisco, and A. Scopa. 2012. Berry morphology and composition in irrigated and nonirrigated grapevine (Vitis vinifera L.). J. Plant Physiol. 169:1023-1061.

Talcott, S., C. Brenes, D. Pires, and D. Pozo-Insfran. 2003. Phytochemical stability and color retention of copigmented and processed muscadine grape juice. J. Agr. Food Chem. 51:957-963.

Talcott, S. and J. Lee. 2002. Ellagic acid and flavonoid antioxidant content of muscadine wine and juice. J. Agr. Food Chem. 50:3186-3192.

Zhu, L., Y. Zhang, and J. Lu. 2012. Phenolic contents and compositions in skins of red wine grape cultivars among various genetic backgrounds and originations. Intl. J. Mol. Sci. 13: 3492-3510. 